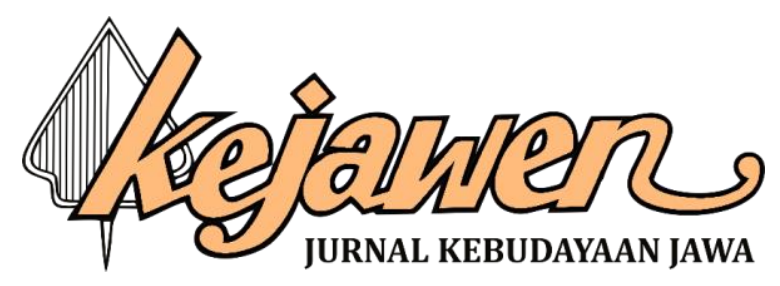

\title{
MISTISISME ISLAM-JAWA DALAM RITUAL HAUL R.M. IMAN SOEDJONO DI PASAREAN GUNUNG KAWI
}

\author{
Dwi Sulistyorini \\ Fakultas Sastra, Universitas Negeri Semarang \\ shoelistr@yahoo.co.id
}

\begin{abstract}
Abstrak
Penelitian ini bertujuan menganalisis mistisisme dengan perspektif simbol dan fungsi sosial religi pada ritual haul R.M. Iman Soedjono di pasarean Gunung Kawi. Ritual haul tersebut dilaksanakan setiap tanggal 12 Sura. Penelitian ini merupakan penelitian deskriptif kualitatif dengan landasan interpretatif. Data primer penelitian ini ritual haul R.M. Iman Soedjono, sedangkan data sekunder dari buku, jurnal, media massa, media sosial, maupun youtube terkait haul R.M Iman Soedjono. Sumber data penelitian informan, tempat dan peristiwa, dokumen. Analisis data dengan model analisis interaktif, melalui empat tahapan, yaitu pengumpulan data, reduksi data, penyajian data, analisis data, dan penarikan kesimpulan. Ritual haul R.M. Iman Soedjono mencerminkan budaya Islam dan Jawa. Tata cara ritual haul menerapkan laku budaya Jawa dan doa-doa yang dibacakan menggunakan bacaan ajaran Islam. Sesaji dan atribut yang digunakan dalam ritual mempunyai makna simbolik yang terkandung di dalamnya. Kebersamaan, gotong royong, toleransi antar umat beragama dan etnik tercermin pada acara haul tersebut.
\end{abstract}

Kata kunci: mistik, ritual, simbol

\section{ISLAMIC-JAVANESE MYSTICISM IN RITUAL HAUL R.M. SOEDJONO IN THE PASAREAN MOUNT KAWI}

\begin{abstract}
The research is intended to analyze mysticism in the perspective symbol and religious social function the haul R.M Iman Soedjono in pasarean mount Kawi. The ritual haul implemented every 12th Sura. The research uses a qualitative research design with interpretative base. Primary data research the ritual haul R.M. Iman Soedjono, while the secondary data from books, journals, mass media, social media, and youtube related haul R.M. Iman Soedjono. The data sources of this research are informants, events, and documents. The data analysis technique was performed using an interactive analysis model, consisting of data collection, data reduction, data interpretation, and conclusion drawing. R.M. Iman Soedjono ritual haul relect Islamic and Javanese culture. Ritual haul procedure practise apply Javanese cultural and pray with Islamic doctrine. The offering and attribute used in the ritual have a symbolic meaning in them. Togetherness, mutual cooperation, tplerence between religious, and etnic were reflected in the haul event.
\end{abstract}

Keywords: mysticism, ritual, symbol

\section{PENDAHULUAN}

Apabila berbicara tentang Gunung Kawi sangat menarik untuk dikaji dari berbagai perspektif. Gunung Kawi dikenal sebagai gunung mistis karena dikenal masyarakat luas bahwa Gunung Kawi sebagai tempat untuk ngalab berkah. Terkenalnya tersebut karena banyak peziarah yang datang ke Gunung Kawi untuk ngalab berkah di pasarean Gunung Kawi dengan tujuan yang beragam dengan keyakinannya masing-masing. Pasarean Gunung Kawi sebagai tempat makam 
laskar dan penasehat spiritual Pangeran Diponegoro yaitu Eyang Djoego (Kanjeng Kyai Zakaria II) dan R.M. Iman Soedjono. Semasa hidupnya kedua tokoh tersebut dikenal sebagai tokoh yang sakti, ahli dalam pengobatan, pertanian, dan suka berbagi. Keberkahan yang diperoleh setelah berziarah di pasarean kedua tokoh tersebut menimbulkan kepercayaan masyarakat yang kuat, sehingga banyak orang yang berziarah ke pasarean Gunung Kawi tersebut.

Pasarean Eyang Djoego dan R.M. Iman Soedjono terletak di lereng Gunung Kawi Gunung. Dalam tataran Triloka suatu gunung, terdiri dari (1) Bhurloka merupakan bagian kaki gunung sebagai tempat hidup manusia dan berbagai hewan, (2) Bhuwarloka merupakan bagian lereng tengah gunung, tempat hidup kaum pertapa, para rsi, dan orang-orang suci yang telah berhasil menindas hasrat duniawi, (3) Swargaloka merupakan tempat persemayaman para dewa (Munandar, 2016:29). Lereng tengah Gunung Kawi sebagai pasarean Eyang Djoego dan R.M. Iman Soedjono berada pada tataran Bhuwarloka. Tempat persemayamannya di lereng Gunung Kawi agar dekat dengan nirwana sehingga sukmanya bisa naik ke Swargaloka. Sedangkan dalam budaya Jawa, mistik kejawen atau kebatinan dalam aktivitasnya ingin mencari hakikat alam semesta, intisari kehidupan, dan hakikat Tuhan. Cara-cara pendekatan diri kepada Tuhan esensinya ada dua hal yaitu proses sangkan paraning dumadi dan memayu hayuning bawana. Konsep sangkan paraning dumadi akan membicarakan ajaran tentang Tuhan, asal mula jagat raya, asal mula manusia sebagai jagat kecil, kelepasan dan kesempurnaan. Sedangkan memayu hayuning bawana berkaitan dengan usaha manusia menjaga, melestarikan, dan mengembangkan dunia sebagai bekal menuju Tuhan (Endraswara, 2006:22-23). Keberadaan alam semesta beserta manusia diciptakan oleh Tuhan dan akan kembali lagi kepada penciptanya. Dalam filosofi Jawa sangkan paraning dumadi mengajarkan tujuan akhir dari kehidupan manusia di alam semesta ini adalah Gusti Sang Hyang Widhi. Ajaran tentang Tuhan, hubungan manusia dengan alam, dan apa tujuan manusia diciptakan Tuhan. Oleh karena itu, manusia mencari nilai-nilai ketuhanan yang dapat dijadikan bekal menghadap Tuhan.

Arwah Eyang Djoego dan R.M. Iman Soedjono bersemayam di lereng Gunung Kawi diyakini peziarah dekat dengan nirwana. Andalas (2014:60; 2017:5) dan Koentjaraningrat (1994:338), menjelaskan bahwa arwah leluhur yang telah menetap di makam maupun yang tinggal di surga dekat Tuhan, masih akan dipuja dan dipanggil oleh para keturunannya untuk memberi nasehat kepada mereka mengenai persoalan rohaniah maupun material. Dalam hal ini dapat dicermati bahwa anggapan masyarakat, khususnya Jawa makam leluhur maupun orang yang mempunyai kharisma merupakan tempat yang keramat sehingga menimbulkan makna yang menyiratkan simbol-simbol berkaitan dengan kehidupan yang bersifat religi. Adanya keyakinan terkait bentuk kontak rohaniah atau spiritual yang dapat terjadi dengan arwah leluhur maupun tokoh yang dikeramatkan. Mereka berkeyakinan arwah-arwah leluhur tersebut dapat menghubungkan doa-doa yang dipanjatkan ke nirwana. Berkaitan dengan hal itu, maka dilakukan ritual di makam-makam para leluhur atau orang yang mempunyai kharisma, seperti halnya ritual di pasarean Gunung Kawi.

Ritual merupakan perilaku sosio-religius yang diulang; rantai tindakan, ritus, atau gerakan ritual mengikuti prosedur-prosedur yang telah ditetapkan (Pentikainen, 1997:733). Artinya, ritual merupakan bentuk ekspresif utama dari agama apapun yang bermuatan simbol-simbol dan nilainilai penting keagamaan. Ritual menjadi prosesi upacara keagamaan yang didasarkan pada nilainilai spiritualitas dan tata cara keagamaan suatu agama. Berbagai bentuk mengenai tata cara dilaksankannya ritual yang berbeda antara satu kebudayaan dengan yang lainnya. Pandangan tersebut sejalan dengan pandangan Koentjaraningrat, (1985:56), yang melihat ritual sebagai tata cara dalam upacara atau perbuatan keramat yang dilakukan oleh sekelompok umat beragama yang ditandai dengan adanya komponen waktu, tempat, alat, serta peserta ritual dilakukan. Berkaitan dengan komponen tersebut ritual haul R.M. Iman Soedjono selalu dilakukan pada tanggal 12 Sura yang bertempat di kompleks pasarean Gunung Kawi. Ritual tersebut dilengkapi dengan sesaji maupun peralatan yang mendukung jalannya ritual, dan diikuti oleh juru kunci, pengurus yayasan 
Ngesti Gondo, utusan dari keraton Mataram baik dari Yogyakarta maupun Surakarta, para keturunan Nitidirejo, sesepuh desa, kepala desa, Muspika (Musyawarah Pimpinan Kecamatan), serta dapat diikuti para peziarah dari berbagai etnis. Acara ritual haul R.M. Iman Soedjono ini tiap tahun dilaksanakan secara rutin.

Tujuan utama ritual haul R.M. Iman Soedjono untuk mengenang almarhum, memberi penghormatan kepada arwah leluhur yang dimakamkan di pasarean tersebut, sebagai ungkapan syukur berkat jasa beliau masyarakat Gunung Kawi dapat melangsungkan kehidupannya dengan tentram, memohon pengayoman dan perlindungan kepada Sang Hayang Widhi. Rangkaian ritual R.M. Iman Soedjono ini membawa daya tarik tersendiri karena ada kirab dan pakaian yang dikenakan pun seragam berwarna hitam dan khas Jawa, kecuali para peserta ritual di luar keturunan keluarga besar Nitidirejo. Dalam pelaksanaan ritual haul R.M. Iman Soedjo92no ini mencerminkan adanya mistisisme Islam Jawa. Doa-doa yang dilantumkan menggunakan bahasa Jawa dan membaca Yasin maupun Tahlil sebagaimana ajaran agama Islam untuk mendokaan orang yang sudah meninggal. Seni tradisi karawitan dan campursari juga digelar dalam acara ritual ini. Nilai-nilai spiritual dan laku kejawen pun masih kelihatan kental dan mengadung mitos maupun makna simbolik yang terselubung di dalam rangkaian ritual tersebut.

Untuk mencapai kesempurnaan hidup, manusia ingin mendekatkan diri kepada Tuhan disebut dengan mistik. Dalam Kamus Besar Bahasa Indonesia (2009:921). secara harfiah mistik adalah subsistem yang ada dalam hampir semua agama dan sistem religi untuk memenuhi hasrat manusia mengalami dan merasakan emosi bersatu dengan Tuhan. Herusatoto (2001:1) menegaskan mistisisme merupakan bagian dari kehidupan masyarakat Jawa. Ia memeiliki budaya khas dimana di dalam sistem atau metode budayanya digunakan simbol-simbol sebagai media untuk menitipkan pesan atau nasehat kepada bangsanya. Mengacu pengertian tersebut dapat dikatakan bahwa mistisisme terkait dengan kepercayaan akan kebenaran tentang realitas dapat diperoleh melalui simbol-simbol dan pengalaman intuitif suprarasional. Mistisisme yang berkaitan dengan spiritual ini ini juga dikenal oleh Islam. Dalam Islam, konsep perjalanan batin spiritual atau proses perjalanan mistik disebut tasawuf atau sufisme yang biasa dilakukan dalam aliran tarekat (Nasution, 1978:50 dalam Nawafi, 2020:243). Ajaran Islam yang dibawa oleh pendahulu kita dengan pendekatan kultural. Oleh sebab itu, dalam acara ritual pun masih digunakan ajaran tersebut, perpaduan Islam Jawa. Dalam ritual haul R.M. Iman Soedjono juga memadukan Islam dan Jawa.

\section{METODE}

Penelitian ini merupakan penelitian deskriptif kualitatif. Tujuan penelitian ini mengungkap secara mendalam dan holistik terhadap sejumlah fenomena yang dipelajari karena landasan yang digunakan adalah interpretatif (Fetterman, 1989). Pemahaman fenomena yang dialami subjek penelitian dimaksudkan untuk mengeksplorasi dan memahami makna yang bersumber dari lingkungan sosialnya (Cresswell, 2014:4). Artinya, upaya eksplorasi dan pemahaman makna dilakukan terhadap fenomena ritual haul R.M. Iman Soedjono.

Data yang digunakan dalam penelitian ini terdiri dari data primer dan sekunder. Data primer penelitian ini, yaitu hasil wawancara dengan informan terkait ritual haul R.M .Iman Soedjono dan hasil pengamatan peneliti terhadap peristiwa yang terjadi pada pelaksanan ritual R.M. Iman Soedjono. Sedangkan data sekunder penelitian ini, yaitu tulisan yang berkaitan dengan masalah penelitian yang berasal dari buku, jurnal, media massa, media sosial, maupun youtube terkait haul R.M Iman Soedjono. Sumber data penelitian ini adalah (1) informan, (2) tempat dan peristiwa, (3) dokumen. Dalam penelitian ini informan kunci, yaitu (1) juru kunci pasarean Gunung Kawi, (2) ketua Yayasan Ngesti Gondo, (3) Sesepuh desa, (4) pengujub doa dalam ritual, dan (5) peserta ritual. Teknik pengumpulan data dilakukan dengan (1) wawancara mendalam, (2) obervasi partisipasi, dan (3) studi dokumen. 
Instrumen penelitian berupa 1) peneliti, 2) panduan wawancara, 3) catatan lapangan, dan 4) alat rekam. Peneliti dalam penelitian ini bertindak sebagai instrumen karena peneliti merupakan perencana, pelaksana pengumpulan data, analis, penafsir data, dan pelapor hasil penelitian (Moleong, 2014:168). Analisis data penelitian ini dilakukan dengan model analisis interaktif, yaitu analisis data dilakukan bersamaan dengan pengumpulan data. Menurut Miles dan Huberman (1992:23), alur analisis mengikuti model analisis interaktif, melalui empat tahapan, yaitu pengumpulan data, reduksi data, penyajian data, analisis data, dan penarikan kesimpulan.

\section{HASIL DAN PEMBAHASAN}

\section{Ritual R.M. Iman Soedjono}

R.M Iman Soedjono adalah seorang bangsawan yang menjadi panglima perang Pangeran Diponegoro dari keraton Yogyakarta. Beliau sebagai penasehat spiritual Pangeran Diponegoro yang melarikan diri ke wilayah Timur setelah Pangeran Diponegoro tertangkap oleh Belanda, tahun 1830. R.M. Iman Soedjono oleh etnis Tionghoa dipanggil Djie Lo Su artinya Guru yang kedua (Tju, 1953:31). Guru yang pertama yaitu Eyang Djoego. R.M. Iman Soedjono mendapat perintah dari Eyang Djoego untuk babad alas Wonosari yang akan digunakan untuk makamnya kelak. Peristiwa itu didasarkan atas wasiat Eyang Djoego yang menginginkan agar kelak ia dimakamkan di wilayah ini (Prastowardoyo \& Anam, 2009:75). Ketika Eyang Djoego meninggal sesuai dengan wasiatnya dimakamkan di Gunung Kawi tersebut. Setelah Eyang Djoego meninggal tak lama berselang R.M. Iman Soedjono pun wafat pada hari Rabu Kliwon tahun 1876 Masehi atau 12 Sura. Beliau makamkan di samping Eyang Djoego sehingga makam kedua tokoh tersebut dikenal dengan pasarean Gunung Kawi.

Sebagai pengingat meninggalnya R.M. Iman Soedjono maka diadakan haul setiap tanggal 12 Sura dimulai setelah Dhuhur (sekitar pukul 13.00 WIB) selesai menjelang Magrib. Rangkaian acara haul R.M. Iman Soedjono terdiri dari beberapa proses ritual dilaksanakan pada beberapa tempat di komplek pasarean Gunung Kawi. Rangkaian ritual haul, yaitu pembagian angpao, persiapan, pemberangkatan kirab, penjemputan utusan dari Mataram di gapura masuk, setelah itu bersama rombongan menuju ke padepokan R.M.Iman Soedjono untuk berdoa bersama, penyerahan simbol keraton Yogyakarta di depan gapura pintu ketiga (pintu masuk ke pasarean), pembukaan pintu pasarean oleh juru kunci dan utusan dari Mataram, peletakan sesaji di pendapa agung, berdoa bersama di pendapa agung pasarean, ziarah.

Pada ritual haul R.M. Iman Soedjono diikuti oleh pihak yayasan Ngesti Gondo maupun dari keturunan Nitidirejo, utusan keraton Mataraman sebagai peserta inti, sedangkan peserta di luar tersebut ada peziarah, kepala desa, dan Muspika. Pakaian yang dikenakan memakai pakaian adat Jawa, laki-laki memakai beskap dan blangkon, sedangkan perempuan memakai kebaya dan rambut disanggul. Keturunan Nitidirejo mulai dari yang tua sampai dengan anak dan cucunya juga mengenakan pakaian adat Jawa. Pakaian adat Jawa ini dikenakan karena R.M. Iman Soedjono berasal dari Mataram, yaitu dari keraton Yogyakarta. Peserta ritual beragam keyakinan ada yang muslim, kejawen, maupun tridharma. Meskipun berbeda keyakinan tolerensi beragama tetap dijaga dengan baik, sehingga ada keharmonisan diantara mereka. Hal ini sejalan dengan pendapat Huda dan Irma (2019:155), keharmonisan antar umat beragama yang pertama adalah terletak pada sikap toleransi yang dibangun untuk menyikapi kerukunan yang ada. Dengan keharmonisan tersebut menunjukkan hubungan bergama di Indonesia merupakan hubungan kekeluargaan. Hal itu terlihat pada acara ritual di Gunung Kawi.

Pembagian angpao dalam ritual haul R.M. Iman Soedjono dilakukan oleh yang punya hajat, baik muslim, kejawen, maupun tridharma. Pembagian angpao mempunyai tujuan berbagi keberkahan. Selain itu, berbagi makanan dengan makan, minum, ambil kue gratis. Penyedia makanan secara gratis adalah para peziarah yang punya hajat, seperti yang dilakukan oleh Salim seorang pengusaha Salim Group yang sukses dan mendapatkan keberkahan dari pasarean menyembelih sapi dan dimasak oleh pihak dapur yang ada di pasarean untuk makan bersama. 
Siapapun yang datang ke pasarean pada saat haul tersebut dapat menikmati makanan yang sudah disiapkan oleh yang punya hajat atau nadzar. Memagikan makanan dan membagi angpao tersebut seperti yang diajarkan oleh Eyang Djoego dan R.M. Iman Soedjono bahwa jika mempunya rezeki hendaknya dibagikan kepada sesame. Seperti diceritakan awal mula selamatan di pasarean tersebut ketika Eyang Djoego masih hidup banyak orang-orang mengantarkan beras, kambing sebagai ucapan terima kasih, kemudian setelah dimasak dibagikan kepada orang banyak atas nama si pemberi agar berkahnya kembali kepada si pemberi (Tju, 1953:41). Ajaran kedua tokoh tersebut diikuti oleh para peziarah yang telah mendapatkan keberkahan setelah berziarah ke pasarean Gunung kawi. Sejalan dengan ajaran kedua tokoh yang dimakamkan di pasarean Gunung Kawi tersebut sesuai dengan teori solidaritas masyarakat sebagai perwujudan dari teori harmoni kaaljasad al wahid yang dalam ajaran Islam menggambarkan saling melindungi, saling mengisi dan membantu terhadap sesama (Mujahidin, 2018). Senada dengan pendapat tersebut dalam ajaran kejawen mengajarkan agar dalam hidup hendaknya berbuat baik terhadap sesama, jujur, baik karena dalam pandangan Jawa hidup itu hanya sebentar ibaratnya mampir ngombe (Soetrisno, 2002:80). Penjelasan di atas dapat disimpulkan dalam Islam maupun Kejawen pun mengajarkan saling berbagi terhadap sesama akan keberkahan yang telah kita terima.

Persiapan kirab dilakukan agar semua sesaji dan tata cara dalam ritual haul R.M. Iman Soedjono dapat berjalan dengan lancar. Sebelum dilakukan kirab, para petugas yang di dapur pasarean pun sibuk memasak untuk membuat sesaji yang akan dibawa untuk kirab sesaji, memasak makanan dari pemangku hajat atau nadzar yang dihidangkan kepada para pengunjung. Selain itu, para pengunjung sambil menunggu acara kirab dapat menikmati makanan yang disediakan dapat menonton karawitan campusari. Karawitan dan sinden menyuguhkan tembang dan gendinggending sehingga nuansa Jawa pun terasa. Mereka juga mengenakan pakaian adat Jawa sebagai kekhasan bahwa gamelan merupakan ciri khas budaya Jawa. Gamelan yang ditabuh oleh para niyaganya menunjukkan adanya keberagaman suara tetapi dapat bersatu sehingga didengar alunan nadanya indah. Hal ini mencerminkan keberagaman jika bersinergi menjadi satu menjadi harmoni yang selaras. Gamelan maupun tembang merupakan sarana untuk menyebarkan agama Islam di Jawa yang dilakukan oleh Sunan Kalijaga. Acara ritual haul R.M. Iman Soedjono pun tambah semarak dengan disuguhkannya musik tradisional Jawa dan tembang-tembang yang membuat nglaras rasa ing kalbu menambah tersentuh adanya nuansa tradisi Jawa yang masih dilestarikan.

Pemberangkatan kirab ritual haul R.M. Iman Soedjono dipimpin oleh juru kunci diikuti para peserta kirab terutama keluarga besar Nitidirejo. Pemberangkatan kirab dimulai dari depan rumah Juru Kunci (Pak Yana) menuju ke padepokan R.M. Iman Soedjono. Para peserta yang membawa sesaji ritual haul (tumpeng, bunga, dupa, buah, kue, polo pendem) meletakkan di balai dekat padepokan R.M. Iman Soedjono, sedangkan juru kunci dan keluarga inti menjemput utusan dari Mataram dan memberi sambutan di pintu gapura masuk untuk melakukan berdoa bersamasama. Setelah itu, rombongan dari Mataram mengikuti rangkaian acara di padepokan R.M. Iman Soedjono.

Acara di padepokan R.M Iman Soedjono membaca doa bersama yang dipimpin oleh sesepuh desa yaitu Bapak Imam Supardi (65 tahun) diikuti oleh peserta kirab, terutama keluarga inti Nitidirejo. Acara ritual ini diselenggarakan di ruang publik, sehinga terjadi penjagaan privasi di ruang publik tersebut melalui sinkoronisasi oleh pelaku ritual. Privatisasi ini terutama di pendopo agung pasarean dan padepokan R.M. Iman Soedjono (Scheflen\&Ashcraft, 1976 dalam Ayu, 2015). Doa ditujukan kepada Eyang Djoego dan R.M. Iman Soedjono dengan bacaan doa Islam, yaitu tahlil dan sholawat Nabi. Pemimpin doa mengajak peserta ritual dengan mengucap salam terlebih dahulu, seperti berikut.

Pertama, Marilah kita memanjatkan puja dan puji dalam rangka haul beliau, semoga dihaturkan kepada Eyang berdua. Kyai Zakaria dan Raden Mas Iman Soedjono. Kedua, Marilah panjatkan doa kepada sanjungan kita dengan membaca 
sholawat salam yang telah memberikan barokah dan memberi bimbingan tuntunan kepada kita semua.

Kyai Zakaria dan Kanjeng Raden Mas Iman Soedjono

Assalamualaikum Wr.Wb.

Kanjeng Raden Mas Iman Soedjono bika.....

Semoga diberi keselamatan, kesehatan, dan ketentraman untuk kita semua

Sallamullohi Warrohmah Ngalaikum Yawali Alloh (oleh pemimpin doa)

Ya Robbibil Musthofa (pemimpin doa diikuti semua peserta)

Balighmaqosidana Waghfirlanaa Mamadho

Ya Wasyi'al Karomi Muhammadun Sayyidul Kaunaini

Watsaqolaini Walfariqoini Min 'Ubin Wamin 'Ajami

Maulaya Sholli Wa Salim Da iman Abada 'Alan Nabiyyi Wa 'Alil baitikulihimi

Ya Rasulallah Salamun 'Alaika (pemimpin doa)

Ya Rofi 'Asyani Waddaroji Ahlul Baitil Musthofa (pemimpin doa diikuti semua peserta)

\section{Thuhurihum Amanul Ardhi Faddakiri}

Ya Rasulalloh Salamun 'Alaika (pemimpin doa)

Ya Rofi 'Asyani Waddaroji Robbi Fanfa'na bibarkati Wahdinal Husna bihurmatihim

Ya Robbibil Musthofa Balighmaqosidana Waghfirlanaa Mamadho

Ya Wasyi'al Karomi Huwal Habibulladzi Turjan Syafa'atuhulikulli

Haulan Minal Awali Mukhtaqomi Maulaya Sholli wa Salim Da iman Abada

'Alan Nabiyyi Wa 'Alil baitikulihimi

Ya Robbibil Musthofa Balighmaqosidana Waghfirlanaa Mamadho Ya Wasyi'al Karomi

Pembacaan doa di padepokan R.M. Iman Soedjono tersebut diikuti oleh semua peserta meskipun berkeyakinan bukan Islam, mereka tetap mengikuti pembacaan sholawat nabi tersebut. Hal ini menunjukkan adanya manajemen konflik dan toleransi beragam dalam melaksanakan rangkaian acara ritual haul R.M. Iman Soedjono. Setelah pembacaan doa selesai, dilanjutkan dengan rangkaian kirab sesaji menuju pasarean. Namun, sebelum masuk pasarean ada acara penyerahan simbol Mataram dari utusan Mataram kepada ahli waris yang diwakili oleh juru kunci makam di depan pintu gapura masuk pasarean. Penyerahan simbol tersebut menunjukkan adanya hubungan historis antara keraton Yogyakarta Hadiningrat sebagai asal-usul R.M. Iman Soedjono dengan Gunung Kawi. Dengan adanya penyerahan simbol tersebut mewujudkan ikatan persaudaraan antara Mataram dan Gunung Kawi terjalin dengan baik. Dalam hal ini sebagai implementasi dari nilai-nilai kearifan lokal dengan adanya rasa persatuan, kebersamaan, saling menghormati dan menghargai. Seperti yang dikatakan oleh Yance (2019) bahwa kearifan lokal dapat dipakai untuk menjaga persatuan dan kesatuan anak bangsa dengan konsep Pancasila sebagai ideologi bangsa. Persatuan dan kesatuan berdasarkan ideologi Pancasila tercermin pada ritual yang dilaksanakan di pasarean Gunung Kawi. 
Acara dilanjutkan menuju ke pendapa agung pasarean Gunung Kawi. Sebelum masuk ke pendapa agung pasarean, dilakukan ritual membuka pintu pasarean oleh juru kunci dan utusan dari Mataram. Ritual tersebut ibaratnya kulanuwun (Jawa), mohon izin kepada Eyang Djoego dan Kanjeng R.M. Iman Soedjono untuk masuk ke pendapa agung. Hal itu sesuai dengan etika Jawa bahwa Ketika bertamu ke rumah seseorang diharuskan mengucap salam karena sebagi bentuk memberikan penghormatan kepada yang menempati rumah tersebut atau yang mempunyai rumah (tuan rumah). Setelah pintu dibuka oleh juru kunci, para peserta yang membawa sesaji masuk terlebih dahulu untuk meletakkan sesaji di dekat makam. Kemudian dilanjutkan berdoa bersama dengan membaca sholawat nabi seperti yang dilakukan di padepokan R.M. Iman Soedjono. Namun yang memimpin doa di pendapa agung adalah pengujub yang biasa membaca doa ketika para peziarah melaksanakan selamatan di pendapa agung.

Puncak acara ritual haul R.M. Iman Soedjono yaitu ziarah ke makam secara bergiliran. Ketika mendekat ke makam para peziarah berjalan jongkok, dan bunga yang dibawa diterima oleh petugas yang ada di dekat makam. Selesai ziarah, para peziarah mendapatkan dua bungkusan yang berisi bunga dan dupa (kemenyan). Bunga dan kemenyan merupakan ciri khas untuk berziarah kubur atau nyekar ke makam-makam yang biasanya dikeramatkan. Bunga dan kemenyan berbau harum semerbak sebagai media untuk ziarah kubur. Dalam mistik kejawen biasanya menggunakan dupa sebagai pengantar sesajen dan makanan serta menghantarkan doa-doa ke alam ora kasad mata. Wewangian ini disukai oleh penghuni alam ora kasad mata. Pada sisi ajaran Islam seperti yang dilakukan Nabi Muhammad SAW, beliau senang dengan tempat-tempat yang harum, pakain harum dengan menggunakan wewangian. Hal ini dapat dilihat tempat-tempat peribadatan muslim banyak yang berbau wangi atau harum dimana tempat ibadah tersebut juga sebagai tempat untuk berdoa. Dengan adanya kemiripan tentang wewangian atau bau harum dalam mistik Kejawen dan Islam menunjukkan adanya seiring sejalan tentang konsep wewangingan hanya berbeda medianya.

\section{Makna dan Simbol dalam Ritual R.M. Iman Soedjono}

Dalam tradisi Jawa peringatan kematian atau haul dilaksanakan pada tahun kematian leluhur yang dihormatinya. Pelaksanaan haul sesuai petunjuk yang mempunyai hajat atas keputusan bersama karena dilaksanakan secara kolektif. Puncak rangkaian acara haul R.M. Iman Soedjono ini ziarah kubur di makam Eyang Djoego dan R.M. Iman Soedjono merupakan perwujudan ekspresi kultural keagamaan. Istilah haul berasal dari Bahasa Arab al-haul yang berarti tahun. Istilah haul biasanya digunakan oleh umat muslim untuk peringatan kematian pada orang yang dihormati. Budaya lokal dan nilai Islami tercermin pada peringatan haul R.M. Iman Soedjono. Pada acara haul tersebut sebenarnya berorientasi pada spiritual yang dalam pelaksanaannya budaya lokal dan nilai-nilai Islam bercampur jadi satu sehingga adanya lokalitas masih tampak. Pada saat membuka pintu pendapa agung pasarean Gunung Kawi, juru kunci menggunakan laku budaya Jawa, tetapi ketika berdoa bersama di dalam pendapa agung menggunakan doa-doa Islam dengan membaca sholawat Nabi. Demikian pula dalam ritual haul ini juga menggunakan sarana sesaji, bunga, dupa sebagai media untuk menghantarakan doa-doa yang dipanjatkan. Fakta ini menunjukkan simbol budaya Jawa dan Islam menyatu seiring sejalan untuk mencapai tujuan yang sama, yaitu berdoa untuk Kyai Zakaria (Eyang Djoego) dan Kanjeng R.M. Iman Soedjono. Setelah Islam masuk ke Indonesia, maka hubungan budaya Jawa dan Islam semakin erat. Relasi budaya Jawa dan Islam ini memunculkan adanya sinkritesme. Sinkritesme Islam berkembang di Jawa karena Islam yang masuk ke Indonesia adalah Islam yang mendapat pengaruh unsur-unsur mistik dari Persia dan India dan cocok dengan pandangan hidup orang Jawa (John L Eposito, 1995:218). Percampuaran Islam dan Jawa dalam ritual haul R.M. Soedjono ini merupakan bersatunya tata nilai budaya Jawa dan Islam.

Keunikan dalam ritual haul R.M. Iman Soedjono ini ada acara pembagian angpao. Apabila ditilik pembagian angpao merupakan tradisi masyarakat Tionghoa. Hal ini terjadi karena para peziarah di pasarean Gunung Kawi mayoritas etnis Tionghoa. Mereka rata-rata mendapatkan 
keberkahan dalam berziarah ke makam kedua tokoh yang dimakamkan di pasarean tersebut. Oleh karena itu, sebagai ungkapan syukurnya pada saat haul R.M. Iman Soedjono, mereka berbagi angpao maupun makanan secara gratis. Pemberian angpao mempunyai makna transfer kesejahteraan atau transfer energi dengan kata lain berbagi terhadap sesama. Transfer kesejahteraan ini dalam Islam juga diajarkan dengan sebutan sedekah atau memberi zakat. Dalam budaya Jawa juga dikenal dengan andum berkat artinya menikmati keberkahan atau rezeki bersama-sama. Hal ini menunjukkan ekspresi simbolik adanya persamaan dalam ajaran Islam dan budaya Jawa. Demikian pula pakaian yang dipakai dalam ritual menggunakan pakaian adat Mataram yaitu blangkon, beskap, jarit, kebaya, sanggul bagi perempuan dengan dandanan yang rapi. Pakaian adat Jawa tersebut menutupi anggota tubuh atau auratnya tertutup rapi. Hal ini mencerminkan adanya kesantunan, kerapian sehingga elok dipandang sesuai dengan filosofi Jawa yang mengajarkan ajining diri saka lati, ajining raga saka busana artinya orang dihargai dari perkataannya atau lisannya dan pakainnya.

Pakaian yang dikenakan oleh peserta ritual haul R.M. Iman Soedjono berwarna hitam. Warna hitam merupakan simbol perlindungan. Artinya dalam ritual ini terdapat permohonan untuk mendapatkan perlindungan dari Tuhan Yang Kuasa. Warna hitam dalam konteks budaya biasanya dipakai dalam beragam kegiatan adat masyarakat, seperti ritual, pengambilan sumpah para tokoh, pesta pernikahan, dan untuk melayat kematian. Sedangkan di Batak, warna hitam mempunyai simbol kerahasiaan, kewibawaan, dan kepemimpinan, simbol dunia bawah. Adapun di Minangkabau warna hitam sebagai simbol kebesaran yang melambangkan ketahanan dengan kekayaan akal dan budi (Edison, 2020). Dalam hal ini warna hitam tidak selalu berkonotasi dengan hal-hal negatif tetapi juga sebagai simbol sesuatu yang positif.

Pada acara ritual haul R.M. Iman Soedjono ini ada penyerahan simbol Mataram kepada ahli waris Eyang Djoego sebagai simbol adanya hubungan sosial. Adanya jejak historis antara keraton Yogyakarta dengan pasarean Gunung Kawi karena Eyang Djoego dan R.M Eyang Soedjono berasal dari Mataram, maka menimbulkan legitimasi pada keberadaan pasarean Gunung Kawi dan ritual yang dilakukan di pasarean tersebut. Dalam ritual di pasarean Gunung Kawi menunjukkan adanya nilai-nilai spiritualitas Jawa yang melekat kuat. Nilai spiritual ini berkaitan dengan hal-hal yang sakral dan agung karena karena mempunyai hubungan langsung dengan Tuhan. Dalam tradisi Jawa, konsep spiritualitas dikenal dengan sebutan olah rasa (penghalusan rasa) yang bertujuan untuk menemukan puncak rohani kepada Tuhan dengan ketenangan jiwa maupun ketentraman batin. Islam-Jawa menyebutnya dengan istilah Manunggaling Kawula Gusti. Endraswara (2006:7), menegaskan alam hidup manusia oleh Tuhan diberikan arah agar orang Jawa tidak salah arah. Arah tersebut dinamakan keblat papat lima pancer, artinya empat penjuru dan satu di tengah. Diawali dari Timur (wetan) artinya kawitan (mula), yang kedua Selatan (lambang darah), Barat (lambang pusar), dan Utara (lambang ari-ari). Hal ini menjelaskan bahwa manusia di alam semesta ini dijaga dari empat penjuru sehingga bagaimana manusia dapat menjalin hubungan harmonis dalam menjalankan kehidupan.

Untuk menjaga keharmonisan manusia dengan alam maka dilakukan berbagai ritual maupun selamatan. Pada dasarnya ritual adalah social performance yang berguna untuk mengomunikasikan ulang simbol-simbol dan menegaskan kembali batas-batas (Govers, 2006:12 dalam Indiyanto, 2014:318). Simbol-simbol dalam ritual terselubung adanya makna yang akan disampaikan. Masyarakat Jawa melakukan tradisi selamatan bertujuan untuk memperoleh keselamatan, ketentraman bagi yang mempunyai hajat. Geertz (1989:126) menjelaskan selamatan merupakan upacara kecil dalam religius Jawa. Tradisi selamatan budaya Jawa dilengkapi dengan sesaji seperti tumpeng, ayam ingkung, telor, urap-urap (sayuran yang berasal dari hasil pertanian), kue berbahan dasar dari hasil pertanian seperti tela, singkong, jagung, dan buah-buahan. Pada ritual haul R.M. Iman Soedjono, sesaji ini pun hadir sebagai pelengkap ritual untuk hidangan para leluhur. Makna simbolik dari sesaji hasil bumi pertanian tersebut menunjukkan adanya kesuburan tanaman yang ada di daerah Gunung Kawi. Tumpeng ingkung berbentuk kerucut sebagai simbol 
ungkapan syukur kepada Tuhan yang telah memebrikan ketentraman, kemakmuran, kesehatan, dan dijauhkan dari pageblug serta marabahaya. Sesaji merupakan wujud aktualisasi dari pikiran dan keinginan dari pelaku ritual untuk mendekatkan diri kepada Tuhan melalui leluhurnya. Dalam Islam selamatan dilakukan dengan doa bersama seorang pemimpin dilanjutkan makan bersama. Tujuannya agar mendapatkan perlindungan dari Tuhan. Selamatan dalam perspektif Jawa maupun Islam mempunyai tujuan yang sama yaitu memohon perlindungan keselamatan kepada Tuhan. Demikian pula ritual yang dilakukan di pasarean Gunung Kawi juga bertujuan memohon perlindungan dan ketentraman manusia yang mempunyai hajat.

Rangkaian acara ritual haul R.M. Iman Soedjono di pendapa agung pasarean diakhiri dengan membaca doa bersama dengan tuntunan Islam dan dilanjutkan ziarah ke makam kedua tokoh yang disemayamkan di pendapa tersebut. Setelah berziarah, para peziarah diberi dua bungkusan yang berisi bunga dan dupa (kemenyan) yang sudah diberi doa dan diasap-asapkan di dupa yang berada di depan pusara kedua tokoh tersebut. Kegunaan bunga dan dupa yang dibawa dari pasarean itu tergantung keperluan individunya masing-masing. Karena setiap individu memiliki alasan yang beragam mempunyai tujuan yang berbeda ketika mengikuti ritual di pasarean Gunung Kawi. Senada dengan pendapatnya Bourdiue (1993) bahwa ritual merupakan sebuah arena (field) dimana setiap aktor berinteraksi, menegosiasikan kepentingan, menciptakan strategistrategi, dan menciptakan makna-makna baru. Sebagaimana hasil wawancara pada tanggal 29 Juli 2020 dengan informan yang bernama Tio Chun Hwi (Wijaya nama di Indonesia) seorang etnis Tionghoa ketika ziarah ke pasarean Gunung Kawi dan melakukan ritual mempunyai keyakinan bahwa melalui bungkusan bunga dan dupa (kemenyan) yang sudah diberi doa dan dipasang di rumah atau tempat usaha-usahanya seperti toko, pabrik, rumah makan maka akan mendapatkan keberkahan dan perlindungan dari Tuhan. Hal itu sesuai dengan budaya Tiongkok dan ajaran dari leluhurnya. Ritual merupakan mengagungkan dan menghormati para leluhurnya, sehingga apapun yang dilakukan dan diberikan dalam berziarah di pasarean Gunung Kawi merupakan sesuatu yang sakral dan mempunyai makna tersendiri.

\section{Fungsi Sosial Budaya}

Penyelenggaraan ritual di pasarean Gunung Kawi bermacam-macam, salah satunya ritual haul R.M. Iman Soedjono pada tanggal 12 Sura. Berbicara ritual tentunya dilakukan oleh komunitas yang melibatkan banyak orang. Adanya ritual ini tidak terlepas dari struktur, fungsi dan makna yang tercermin didalamnya. Hal itu tentunya berkaitan erat dengan sosial budaya yang ada di masyarakat pemiliknya. Dalam ritual haul R.M. Iman Soedjono, peserta kirab sesaji berbagai lapisan masyarakat dengan etnis yang beragam dan keyakinan yang berbeda berkumpul bersama mendukung acara tersebut. Mereka berinteraksi satu dengan yang lain dalam berkoordinasi, bergotong royong, berkomunikasi secara kekeluargaan menumbuhkan rasa kebersamaan dan persaudaraan. Toleransi antar umat beragama dalam cara ritual ini merupakan pondasi dari fungsi sosial yang telah dibangun.

Tradisi ritual haul ini secara rutin dilakukan setiap tahunnya. Hal ini menunjukkan adanya pewarisan budaya yang tetap dijaga dan dilestarikan dari generasi satu ke generasi berikutnya. Secara simbolik dalam acara ritual haul ini mewujudkan adanya fungsi sosial dengan terjalinnya hubungan antara individu yang satu dengan yang lain, individu dengan kelompok, dan individu dengan masyarakat luas. Sesuai dengan fungsi tradisi bagi masyarakat berpengaruh pada perilaku masayarakat pemiliknya. Sulistyorini (2017:50) mengatakan fungsi dalam tradisi merupakan sesuatu hal yang bermanfaat bagi manusia dan kebudayaan tertentu. Ritual haul R.M. Iman Soedjono memiliki fungsi sosial yang terus berlangsung jika diatur dan dijaga dengan baik sehingga terasa kebermanfaatannya.

Pelaksanaan ritual haul R.M. Iman Soedjono, selain para pengurus yayasan Ngesti Gondo dan keturunan Nitidirejo dihadiri juga oleh utusan dari Mataram, para peziarah, dan pemerintahan desa maupun kecamatan. Jejaring sosial yang baik antara komunitas satu dengan yang lain terjaga 
dengan baik sehingga semua pihak mendukung penyelenggaraan acara ritual ini. Penggerak atau motor dalam jejaring sosial ini adalah pihak yayasan Ngesti Gondo sebagai ahli waris dari R.M. Iman Soedjono yang berhasil menyatukan dalam satu wadah yaitu ritual di pasarean Gunung Kawi. Sebagaimana konsep fiel of cultural yang didengungkan oleh Bourdie dalam konteks ritual menimbulkan adanya arena untuk memahami kontestasi yang ada dalam masyarakat, adanya keterlibatan aktor, negosiasi dan kompromi yang dilakukan oleh yayasan Ngesti Gondo dengan pihak-pihak terkait merupakan modal sosial dengan menjalin jaringan relasi sosial antarindividu maupun kelompok. Namun, hal itu berdampak positif dalam menyatukan umat manusia yang beragam latarbelakangnya maupun keyakinan yang berbeda dalam satu wadah mendukung ritual R.M. Iman Soedjono. Dukungan berbagai pihak dalam ritual tersebut mengisyaratkan adanya refleksi simbolik sebagai pancaran keinginan masyarakat untuk memperoleh fungsi tertentu dalam kehidupan sosial bermasyarakat sebagai makhluk sosial.

Ritual haul R.M. Iman Soejono merupakan perpaduan budaya Islam-Jawa karena dalam pelaksanaan ritual masih memegang teguh laku kejawen dan ajaran Islam. Hal itu tercermin pada tata cara dan aturan dalam ritual, seperti halnya pakaian yang dikenakan pakaian adat Jawa tanpa menggunakan alas kaki, sesaji yang dibawa, bunga dan dupa sebagai media untuk berdoa, pembacaan mantra ketika akan membuka pintu pendapa agung pasarean, para peziarah berjalan jongkok ketika akan berziarah mendekat ke makam. Dalam budaya Jawa, sesaji yang dibawa sebagai persembahan merupakan lambang atau simbol pelengkap kesempurnaan untuk berdoa. Selain itu adanya pertunjukkan campursari yang diiringi gamelan asli membawa nuansa Jawa sangat kental. Doa-doa Islami pun dilantumkan dengan membaca tahlil dan sholawat Nabi oleh peserta kirab sesaji yang ditujukan kepada Eyang Djoego dan R.M. Iman Soedjono. Hal ini secara tidak langsung mengenalkan budaya Jawa dan Islam yang dapat bersatu untuk melengkapi satu dengan yang lain. Simbol budaya dalam ritual tersebut dapat membangun pemikiran positif terhadap keberadaan pasarean Gunung Kawi. Kebudayaan bersifat dinamis berkembang sesuai dengan latarbelakang sosial budaya masyarakatnya.

\section{SIMPULAN}

Ritual haul R.M. Iman Soedjono dilaksanakan sebagai bentuk penghormatan terhadap almarhum yang berjasa kepada masyarakat Wonosari dan memberikan keberkahan terhadap para peziarah. Rangkaian ritual haul tersebut dilaksanakan pada berbagai tempat di komplek pasarean Gunung Kawi. Tempat-tempat tersebut tentunya mempunyai makna dimana sebagai tempat sejarah almarhum R.M. Iman Soedjono. Makna simbolik dalam rangkaian acara haul tercermin dari semua atribut dalam ritual, tata cara ritrual, dan perilaku sebagai gerak-gerik yang merefleksikan makna simbolik. Perpaduan budaya Islam-Jawa sangat kental pada ritual haul R.M. Iman Soedjono ini. Laku kejawen dan ajaran Islam menyatu membentuk kehamornisan yang selaras dalam ritual ini. Terselenggaranya ritual haul R.M. Iman Soedjono ini tentunya didukung oleh berbagai pihak sebagai wujud terbentuknya jejaring sosial dengan segala komponen masyarakat. Ritual ini tidak terlepas dari fungsi sosial maupun budaya yang telah diwariskan oleh leluhur, yaitu adanya kebersamaan, kegotongroyongan, saling menghargai dan toleransi antar sesama. Dalam hal ini mencerminkan bahwa ritual merupakan fenomena sosial yang saling mempengaruhi, melengkapi, dan menjalin rasa persatuan dalam kebersamaan untuk mencapai satu tujuan.

\section{DAFTAR PUSTAKA}

Andalas, E. F. (2014). Mitos Mbah Bajing dalam Sastra Lisan Masyarakat Dusun Kecopokan Kecamatan Sumberpucung Kabupaten Malang. Universitas Negeri Malang.

Andalas, E. F. (2017). Dampak dan Fungsi Sosial Mitos Mbah Bajing bagi Kehidupan Spiritual Masyarakat Dusun Kecopokan Kabupaten Malang Jawa Timur. Puitika, 13 (1), hlm. 2131.

from: http://jurnalpuitika.fib.unand.ac.id/index.php/jurnalpuitika/article/view/48 
Ayu, D., Antariksa, A., \& Ridjal, A. M. (2014). Atribut Ruang sebagai Penanda Ruang Ritual pada Pesarean Gunung Kawi Kabupaten Malang. RUAS, 12 (2), hlm. 32-40. https://doi.org/10.21776/ub.ruas.2014.012.02.4

Bourdieu.P. (1993). The Field of Cultural Production. New York: Colombia University Press.

Cresswell, J. C. (2014). Research Design: Pendekatan Kualitatif, Kuantitatif, dan Mixed. Yogyakarta: Pustaka Pelajar.

Endraswara, S. (2003). Mistik Kejawen: Sinkretisme, Simbolisme, dan Sufisme dalam Budaya Spiritual Jawa. Yogyakarta: Narasi.

Fetterman, D. M. (2010). Ethnography. London: Sage Publication.

Geertz, C. Abangan, Santri, Priyayi dalam Masyarakat Jawa. Jakarta: Dunia Pustaka Jaya.

Herusatoto, B. (2001). Simbolisme dalam Budaya Jawa. Yogyakarta: Hanindita.

Huda, M. Thoriqul Huda dan Irma Khasanah. (2018). Budaya Sebagai Perekat Hubungan Antara Umat Beragama di Suku Tenger. Sangkep: Jurnal kajian Sosial Keagamaan. Vol. 2, No. 2, Juli-Desember 2019 p-ISSN: 2654-6612 e-ISSN 2656-0798

Indiyanto, A. (2014). Kontinuitas dan Diskontinuitas dalam Ritual Mendhak di Tlemang Lamongan. Patrawidya. Vol.15, No.2, Juni 2014.

John L Eposito. 1995. The Oxford Encyclopedia of the modern Islam WORD, III (New York, tnp).

Kamus Besar Bahasa Indonesia. (2009). Cetakan Keempat. Jakarta: Gramedia.

Koentjaraningrat. (1985). Beberapa Pokok Antropologi Sosial. Jakarta: Dian Rakyat.

Lampu Edison. (2020), 16 Juli. Arti Warna Menurut berbagai Budaya di Indonesia. (Online), kumparan.com.

Miles, B. M., \& Huberman, M. (1992). Analisis Data Kualitatif Buku Sumber Tentang Metodemetode Baru. Jakarta: UIP.

Moleong, L. J. (2014). Metodologi Penelitian Kualitatif. Bandung: Remaja Rosda Karya.

Mujadin, Akhamad. (2018). Islam dan Kepemimpinan Sebuah Catatan Untuk Pemimpin dan Calon Pemimpin Muslim. (Online) https://uin-suska.ac.id/2016/04/18/islam-dankepemimpinan-sebuah-catatan-untuk-pemimpin-dan-calon-pemimpin-muslim-akhmadmujahidin/

Munandar, A. A. (2016). Arkeologi Parwitra. Jakarta: Wedatama.

Nawafi, AYF. (2020). Titik Temu Mistisisme Islam dan Mistisisme Jawa: Studi Analitis Persinggungan terhadap Ajaran Tasawuf dan Kejawen. Intelektual: Jurnal Pendidika Encyclopedia dan Studi Keislaman. Volume 10, Nomor 2, Agustus 2020 https://ejournal.iai-tribakti.ac.id/index.php/intelektual/index

Pentikainen, J. (1997). Ritual. In T. A. Green (Ed.), Folklore: An Encyclopedia of Beliefs, Customs, Tales, Music, and Art (pp. 733-736). California: ABC-CLIO.

Prastowardoyo, A., \& Anam, K. (2009). Gunung Kawi: Fakta dan Mitos. Surabaya: Lingua Kata. Soesilo. 2002. Ajaran Kejawen Philosofi dan Perilaku. Cetakan Kedua. Jakarta: Yayasan Yusula. Sulistyorini, D. \& Eggy. A. (2017). Sastra Lisan: Kajian Teori dan Penerapan dalam Penelitian. Malang: Madani.

Sulistyorini, D. (2020). Komersialisasi Potensi Pasarean Gunung Kawi melalui Industri Pariwisata. Disertasi UNS.

Tju, I. Y. (1953). Riwajat Ejang Djugo Panembahan Gunung Kawi. Surabaya: Astagina.

Yance, Hendrik. (2019), 17 November. Indonesia Perlu Kuatkan Nilai Kearifan Lokal. Berita Satu, (Online), https://www.beritasatu.com/politik/585762/hendrik-yance-indonesiaperlu-kuatkan-nilai-kearifan-lokal 